\title{
ANTERIOR SACRAL MENINGOCELE
}

\author{
DAVID T. NOYES, M.D. \\ ROBERT K. VINSON, M.D. \\ JACK LAPIDES, M.D.
}

From the Departments of Urology, University of Vermont

Medical School, Burlington, Vermont, and University of

Michigan Medical Center, Ann Arbor, Michigan

\begin{abstract}
Three cases of an unusual congenital anomaly of the spinal column, anterior sacral meningocele, are reported. A brief review of the literature and discussion are presented.
\end{abstract}

Anterior sacral meningocele is an unusual anomaly consisting of a spinal fluid-filled sac in the pelvis which communicates via a narrow neck with the spinal subarachnoid space. This sac is composed of outer dural tissue and inner arachnoid membrane. Herniation of the dura through bony defects most often occurs posteriorly in the lumbar area; and if it contains neural elements, it is called a myelomeningocele. These defects may occur anywhere along the spinal column or within the calvarium.

Most patients with this lesion have been seen initially by general and gynecologic surgeons for evaluation of pelvic masses, although other surgical specialists have encountered this problem. ${ }^{1-8} \mathrm{~A}$ large increase in reported cases in the last several years suggests the lesion is more common than previously suspected. The urologic literature relating to the anterior sacral meningocele is sparse. The following 3 case reports indicate how these patients may present for urologic attention.

\section{Case Reports}

\section{Case 1}

A twenty-three-year-old man had gradually increasing difficulty in emptying his bladder. This was associated with the onset of severe headaches, nausea, and vomiting. Initial evaluation by his general physician revealed hypertension, $170 / 100 \mathrm{~mm}$. $\mathrm{Hg}$, and a distended bladder with $700 \mathrm{ml}$. residual. Blood urea nitrogen was $58 \mathrm{mg}$. and serum creatinine 2.0 $\mathrm{mg} . / 100 \mathrm{ml}$. He was referred to the University
Hospital for urologic evaluation. Physical examination revealed a distended bladder, intact bulbocavernosis reflex, and normal saddle sensation.

The flat plate of the excretory urogram demonstrated the classic "scimitar" sign of anterior sacral meningocele (Fig. 1A). Excretory urography and cystography revealed severe bilateral hydronephrosis and a trabeculated, thickened bladder without reflux. Cystometry confirmed a motor paralytic bladder. A myelogram revealed the lesion and its origin from the sacral plate (Fig. 1B). The patient did not undergo surgical excision of the lesion but instead a bethanecol (Urecholine) regimen was prescribed. He did well until four years later when acute, bilateral pyelonephritis developed. At that time he was switched to clean intermittent catheterization. The patient has done well on this regimen with his serum creatinine remaining stable at $2.3 \mathrm{mg}$. and blood urea nitrogen at $35 \mathrm{mg} . / 100 \mathrm{ml}$.

\section{Case 2}

A fifty-year-old woman was first seen at the University of Michigan Medical Center for a second opinion regarding the need for a bladder suspension procedure. Her urologic history began in early childhood when she demonstrated signs and symptoms of a neurogenic bladder associated with recurrent attacks of urinary tract infection and pyelonephritis.

In 1972 she underwent a Marshall-Marchetti procedure for her urinary incontinence. Her 

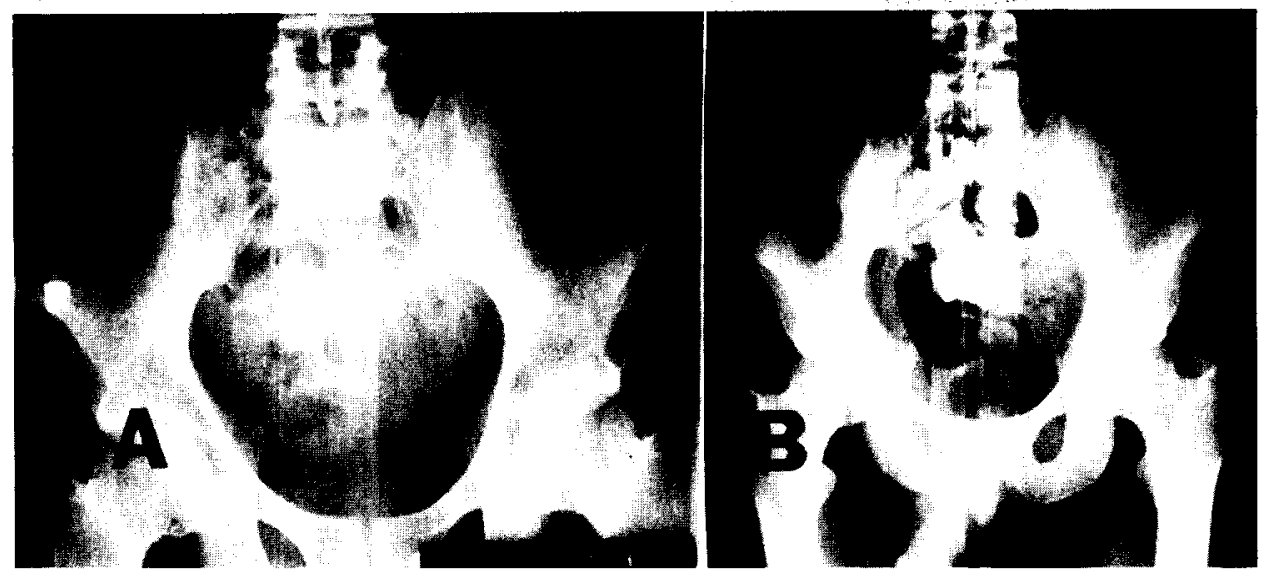

Figure 1. Case 1. (A) Pelvic roentgenogram reveals classic "scimitar" shape of sacrum, and $(B)$ myelogram shows anteriorly placed meningocele.

wetting did not improve, and a vesical diverticulectomy was done. Pollakiuria, stress urinary incontinence, and urinary infection continued after the previous operative procedures. She sought the advice of other urologists who advocated anterior urethropexy.

Her medical history revealed that at age sixteen she underwent a posterior proctotomy for removal of a retrorectal cyst which on biopsy was diagnosed as "cloacal choristoma." System review disclosed that she had been constipated all her life. Her physical examination was essentially within normal limits except for saddle area hypesthesia and anesthesia, hyperactive bulbocavernosus reflex, and an inability to contract the anal sphincter voluntarily.

Urodynamic investigation revealed a mixed type of neurogenic bladder. She had normal proprioceptive sensation, a $200-\mathrm{ml}$. bladder capacity with weak uncontrolled contractions, and a positive bethanecol test result. She voided by straining with a residual of $140 \mathrm{ml}$. Concomitant electromyography of the external sphincter, using monopolar needle electrodes, demonstrated abnormal firing of the motor units and an uncoordinated external sphincter.

At cystoscopy she had trabeculation, cellules, and diverticula of the bladder with a normal left ureteral orifice and a patulous right ureteral orifice. Her urethral length was $2 \mathrm{~cm}$. in a supine position, $1.5 \mathrm{~cm}$. in erect position, and she had loss of urine on stress. The initial film from the excretory urogram revealed severe sacral dysplasia. The left kidney and ureter were normal, but the right kidney showed changes of chronic pyelonephritis. A voiding cystourethrogram revealed grade III reflux on the right. She had a blood urea nitrogen of $17 \mathrm{mg}$. and serum creatinine of $1.0 \mathrm{mg} . / 100 \mathrm{ml}$. The patient's therapy included clean intermittent self-catheterization, oxybutynin chloride (Ditropan), and short-term antibiotics. The patient has been followed for five years, is continent, and has had only one episode of bacteriuria during that follow-up.
Case 3

A six-month-old male infant presented with an abdominal mass approximately $15 \mathrm{~cm}$. in diameter. Rectal examination located its origin as posterior to the rectum. The patient was catheterized for $560 \mathrm{cc}$. of clear, yellow urine. The mass was smaller but still present, and radiologic investigation was begun.

A KUB x-ray film did not show any abnormal calcifications or structural abnormalities. An excretory urogram revealed normal, nondilated upper systems but a markedly displaced and distorted urinary bladder, which was elevated anteriorly and superiorly (Fig. 2). The voiding cystourethrogram showed no reflux. The serum electrolytes were normal; creatinine was 0.4 $\mathrm{mg} . / 100 \mathrm{ml}$. Ultrasound revealed a single, large cystic mass in the pelvis. Urinary vanillylmandelic acid was normal.

During surgical exploration of the abdomen, he was found to have a large cystic mass adherent to the sacral plate filled with $500 \mathrm{cc}$. of clear, straw-colored fluid. This was excised with a watertight closure. The mass has not recurred one year postoperatively, and he voids with an excellent stream without residual.

\section{Comment}

The first reported case of an anterior sacral meningocele was in 1837 by an anonymous surgeon who noted a large cyst obstructing normal delivery. This lesion was identified at autopsy four days later. ${ }^{9}$

Since that time about 120 cases have been reported. ${ }^{10,11}$ There is a marked preponderance in the female adult population, but in the pediatric age group the incidence is equal. It has been postulated that the lesion is more likely to be incidentally discovered in women, because of the large number of associated gynecologic anomalies. They are usually asymptomatic and undetected in males because of their internal location which cannot be visualized like the more common posterior myelomeningocele. 


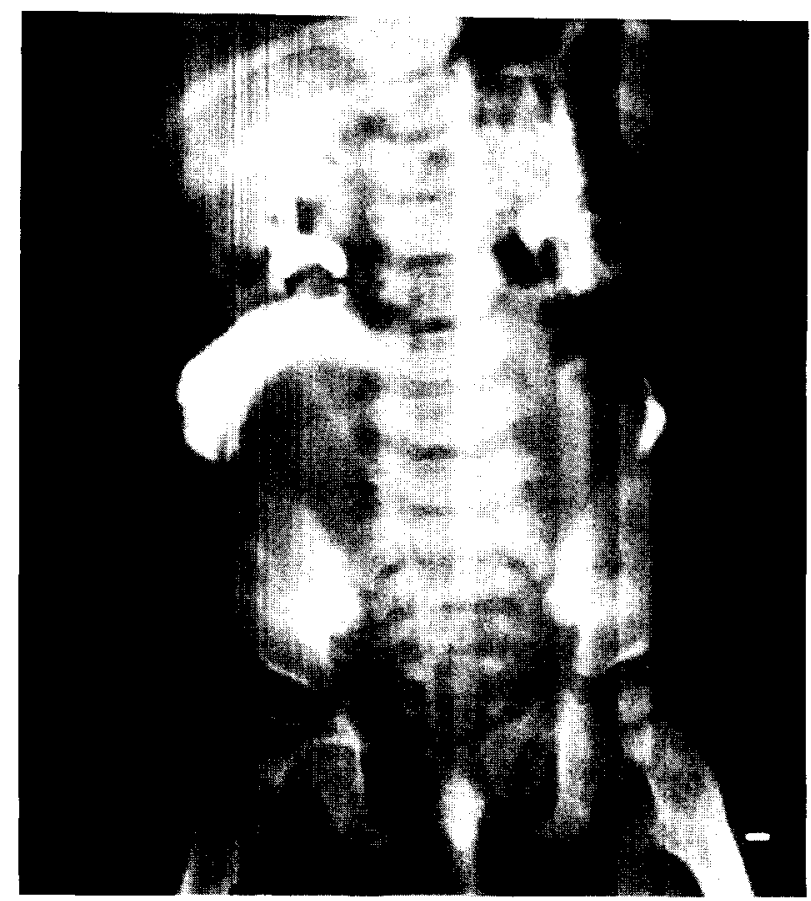

Figure 2. Case 3. Intravenous urogram details marked bladder distortion.

A familial tendency is discussed in recent articles, pointing out the need for examining all family members once the diagnosis is established. $5,7,12,13$ Transmission is thought to be autosomal dominant with variable penetrance.

Symptonatic patients seck medical attention because of three groups of symptoms. Local pressure by the meningocele may cause constipation, urinary retention, or female genital tract complaint of dyspareunia, dysmenorrhea, or protracted labor. Second, patients may have local neurologic deficits such as poor sphincter control, siccral anesthesia, or lower extremity deficits. Finally, patients may complain of central ne ırologic symptoms such as nausea and headache with straining; the result of increased abdominal pressure on the meningocele.

The review by Oren et al. ${ }^{10}$ and subsequent case reports $^{2,12.14,16}$ reveal that primary urinary complaints are unusual and variable. Urinary retention and incontinence have been the most common urinary symptoms followed by cystitis and enuresis. Neurogenic bladder was described in only 6 cases, although it is likely that more would have been discovered if all patients had undergone urodynamic evaluation.

The diagnosis first should be entertained when a retrorectal mass is identified. Naturally this must be distinguished from an osseous tumor, teratoma, dermoid cyst, primary cord tumor, or metastatic lesion. A roentgenogram of the pelvis often will show the classic "scimitar" deformity of the sacrum. Ultrasound is a valuable diagnostic aid and will reveal the mass to be cystic. A myelogram with contrast media or air often will show the narrow stalk and the meningocele. Computerized pelvic scanning ${ }^{17}$ has been proposed as a means of establishing the diagnosis without the need for a myelogram.

The therapy for symptomatic patients is surgery to eradicate the lesion since there have been no reported cases of spontaneous regression. The symptoms improve remarkably with the removal of the mass. Aspiration as a diagnostic or therapeutic measure has been fraught with the complications of meningitis and recurrence of the cyst.

In summary, urologists may identify this lesion when evaluating patients with urinary retention, incontinence, enuresis, or neurogenic bladder. Because of its possible hereditary nature and occultness, a need to examine family members exists. The classic "scimitar sign" defect of the sacrum is not always present on pelvic $x$-ray examination. The urologist should be aware of the possibility of a sensory, motor, or autonomous neurogenic bladder and should perform urodynamic examination on all patients at an appropriate time.

\section{Burlington, Vermont 05401}

(DR. VINSON)

\section{References}

1. Vogel EH: Anterior sacral meningocele as a gynecologic problem, Obstet. Gynecol. 36: 766 (1970)

2. Sumner TE, Crowe JE, Phelps CR, and Park RW: Occult anterior sacral meningocele, Am. J. Dis. Child. 134: 385 (1980).

3. Ivamoto HS, and Wallman LJ: Anterior sacral meningoceles, Arch. Neurol. 31: 345 (1974).

4. Chovnick SD: Anterior sacral meningocele as a cause of urinary retention, J. Urol. 106: 371 (1971).

5. Klenerman L, and Merrick MV: Anterior sacral meningocele occurring in a family, J. Bone Joint Surg. (Br.) 55: 331 (1973).

6. Johnson LH: Pregnancy associated with an anterior sacral meningocele, South. Med. J. 63: 432 (1970)

7. Aaronson I: Anterior sacral meningocele, anal canal duplication cyst and covered anus occurring in one family, J. Pediatr. Surg. 5: $559(1970)$.

8. Shaker IJ, Lenier VC, and Amoury RA: Congenital anal stenosis with anterior sacral meningocele, ibid. 6: 177 (1971)

9. Bryant $T$ : Case of deficiency of the anterior part of the sacrum with a thecal sac in the pelvis similar to the tumor of spina bifida, Lancet 1: 358 (1837).

10. Oren $\mathbf{M}$, et al: Anterior sacral meningocele, Dis. Colon Rectum 20: 492 (1977).

11. Haddadd, FS: Anterior sacral meningocele, report of two cases and a review of the literature, Canad. J. Surg. 1: 230 (1958).

12. Anderson FM, and Burke BL: Anterior sacral meningocele: a presentation of three cases, JAMA 237: 39 (1977).

13. Cohn J, and Bay-Nielsen E: Hereditary defect of the sacrum and coccyx with anterior sacral meningocele, Acta Paediatr. Scand. 58: 268 (1969).

14. de Klerk DJJ, McCusker I, and Loubser JS: Anterior sacral meningoceles, S. Afr. Med. J. 54: 361 (1978).

15. McCreath GT, and Macpherson P: Sonography the diag. nosis and management of anterior sacral meningocele, J. Clin. Ultrasonog. 8: 153 (1980).

16. Felson B, and Spitz HB: Pelvic mass in a twelve-year-old girl, JAMA 237: 1255 (1977).

17. Baleriaux-Waha D, et al: Management of anterior sacral meningocele with CT, Neuroradiology 14: 45 (1977). 